\title{
Identification of the Adduct Between \\ a 4-Aza-3-ene-1,6-diyne and DNA Using \\ Electrospray Ionization Mass Spectrometry
}

\author{
Courtney L. Sherman, Sarah E. Pierce, and Jennifer S. Brodbelt \\ Department of Chemistry and Biochemistry, University of Texas at Austin, Austin, Texas, USA
}

\author{
Bodin Tuesuwan and Sean M. Kerwin \\ Division of Medicinal Chemistry, College of Pharmacy, University of Texas at Austin, Austin, Texas, USA
}

The interactions between a novel enediyne [1-methyl-2-(phenylethynyl)-3-(3-phenylprop-2ynyl)-3H-benzimidazolium] (1) and various cytosine-containing oligonucleotides were studied using electrospray ionization mass spectrometry (ESI-MS) in a flow injection analysis mode useful for small volumes. This enediyne ligand, developed as a potential alternative to the highly cytotoxic natural enediynes, some of which have been successfully used as anti-tumor agents, has previously been shown to interact with DNA through frank strand scission as well as via the formation of adducts that lead to $2^{\prime}$-deoxycytidine-specific cleavage. Through ESI-MS, the structures of these adducts were examined and a sequence dependence of the 2 -deoxycytidine-specific cleavage was noted. Collisionally activated dissociation of the observed adducts confirmed the strength of the interactions between the enediyne and DNA and supports a direct linkage between the enediyne and the cytosine nucleobase, likely the result of a nucleophilic attack of the phenylethynyl group by the cytosine amine. (J Am Soc Mass Spectrom 2006, 17, 1342-1352) @ 2006 American Society for Mass Spectrometry

$\mathrm{F}$ ollowing the initial elucidation of the structure of the neocarzinostatin chromophore [1], much effort has been directed towards identifying additional natural enediynes and evaluating their activities [2-5]. Currently, nearly twenty of these natural enediynes have been identified, including calichemicin $\gamma_{1}^{\mathrm{I}}[6,7]$, dynemicin [8], and the esperamicins $[9,10]$. While these enediynes offer extremely high cytotoxic activities, their clinical use as anti-tumor agents has been limited due to their delayed activities and general toxicity [2-5].

To overcome the shortcomings of these natural enediynes, a range of synthetic analogs have been explored [3,11], each with the goal of improved properties for clinical use. While still capable of cleaving DNA like the natural products through cycloaromatization reactions and subsequent hydride abstraction by the diradical intermediate [2-4, 11, 12], these analogs offer potential advantages, such as more controlled activation of the compound in vivo [13-23] or increased selectivity for tumor cells [24-30].

To better evaluate the activities and properties of the many enediyne drug candidates as well as various

Published online July 26, 2006

Address reprint requests to Dr. J. S. Brodbelt, Department of Chemistry and Biochemistry, University of Texas, 1 University Station A5300, Austin, TX 78712, USA. E-mail: jbrodbelt@mail.utexas.edu other classes of drugs being developed, we present a technique for analyzing the interactions between these compounds and DNA using a flow injection analysis (FIA) mode coupled to an electrospray ionization mass spectrometer (ESI-MS). This analysis offers several key advantages over the traditional gel-based electrophoretic techniques. First, the dramatically better resolution of mass spectrometry versus polyacrylamide gel electrophoresis (PAGE) allows differentiation of similarly sized species, enabling the detection of very small molecules adducted to DNA. Second, while gel electrophoresis typically requires micrograms of sample, with our FIA method, a mass spectrum can easily be collected with nanograms, a sensitivity advantage of up to three orders of magnitude. Lastly, FIA-ESI-MS is easily adaptable to high-throughput analyses [31-33].

In recent years, applications of ESI-MS for DNA analysis have begun to mature [34, 35]. A critical component of many of these experiments is the application of tandem mass spectrometry to probe the fragments produced when DNA ions [34-36], noncovalent DNA-drug complexes [37, 38], or covalent DNA-drug complexes [39-55] are energized in the gas phase. Collisionally-activated dissociation (CAD) [56], infrared multiphoton dissociation (IRMPD) [57, 58], and electron capture dissociation (ECD) [59] have all been demonstrated to yield useful information about oligonucleotides. With respect to covalently bound DNA adducts, 


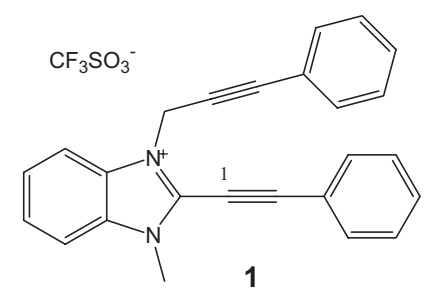

Structure 1

such as the ones discussed in this study, determination of both the position and mode of attachment of a drug or ligand to a DNA sequence has been the primary focus of many of these prior reports [39-55]. Despite the potential advantages in applying ESI-MS to the study of enediyne-DNA interactions, we have found no reports exploring this method.

Previous studies have shown that $\mathbf{1}$ (Structure 1) interacts with DNA in at least three ways: via frank strand scission and the formation of at least two different adducts [29]. One of these adducts subsequently effects specific cleavage of the oligonucleotide sequence at 2'-deoxycytidine residues [29], likely through a mode of action very different from the radical-induced cleavages commonly observed with enediyne drugs [2-5]. It has been proposed that the adduct results from a nucleophilic attack of one of the alkynes on the enediyne by the DNA [28]. The gel electrophoresis experiments used in the discovery of this behavior lacked both the mass resolution to accurately characterize the adducts and the ability to further probe the structures of the adducts. NMR methods, which would offer substantial structural information about the adducts, are not sufficiently sensitive for analysis of the minute quantities of adducts formed from the reactions described herein. In this study, we present an examination of these adducts by ESI-MS. In addition to confirming the information previously obtained by gel electrophoresis, the mass spectrometric analysis reveals the identity and stoichiometry of the adducts. Furthermore, through tandem MS experiments, a series of clues obtained about the structure of the adduct has helped to identify both the location and mechanism of attachment to the oligonucleotide structure.

\section{Experimental}

\section{Reagents}

The oligonucleotides and primers were synthesized on a PerSeptive Biosystems Expedite 8909 DNA synthesizer (Framingham, MA) and purified by reversedphase chromatography. Concentrations were determined by UV absorption at $260 \mathrm{~nm}$. The enediyne, 1, and a version that was ${ }^{13} \mathrm{C}$-labeled at position 1 were prepared according to previously published procedures [27].

\section{Preparation of Samples for Analysis}

Mixtures of the different oligonucleotides at $360 \mu \mathrm{M}$ with $3.6 \mathrm{mM} 1$ were prepared in a $10 \mu \mathrm{M}$ sodium phosphate buffer at either $\mathrm{pH} 6$ or 8 also containing $8 \%$ DMSO (Sigma-Aldrich Corp., St. Louis, MO). These mixtures were then incubated at $37^{\circ} \mathrm{C}$ for $20 \mathrm{~h}$ (dCC) or $24 \mathrm{~h}$ (other oligonucleotides). Following incubation, the samples were desalted either by reversed-phase HPLC (dCC) or with $\mathrm{C}_{18}$ Waters (Midford, MA) Sep-Pak cartridges (other oligonucleotides). Samples were further purified using $\mathrm{C}_{18}$ ZipTips (Millipore, Bedford, MA) immediately before analysis. Additionally, samples with $\mathrm{dCC}$ were prepared identically with a version of 1 containing a ${ }^{13} \mathrm{C}$ isotopic label at carbon one of the phenylethynyl group to assist in identification of fragment ions. Another series of dCC $+\mathbf{1}$ or $\mathrm{dGA}+\mathbf{1}$ samples were incubated as above and then heated to $90{ }^{\circ} \mathrm{C}$ in the presence of $10 \%$ piperidine. The samples were dried and resuspended in 80:20 water/methanol. As above, the hot piperidine treated samples were purified with $\mathrm{C}_{18}$ ZipTips.

\section{Methods and Instrumentation}

Prepared samples were analyzed on a ThermoFinnigan LCQ Duo quadrupole ion trap mass spectrometer equipped with the standard ESI source (San Jose, CA). Injections of $1-5 \mu \mathrm{L}$ for the FIA were made with a Waters Alliance 2690 Separations Module with a carrier flow of A.C.S. grade spectranalyzed methanol (Fisher Scientific, Fair Lawn, NJ) at $10 \mu \mathrm{L} / \mathrm{min}$. Mass spectra were obtained by integrating the signal across the FIA peak. Direct infusion experiments involving the samples of $\mathrm{dCC}+\mathbf{1}$ after hot piperidine treatment were carried out by diluting $5 \mu \mathrm{l}$ of sample in $250 \mu \mathrm{l}$ of 50:50 water:methanol with similar electrospray conditions to the FIA introduced samples. Nomenclature for identifying oligonucleotide fragments followed the conventions set forth by McLuckey et al. [36]

\section{Results and Discussion}

\section{Interactions Between 1 and $d C_{8}$}

Armed with the previous results indicating that $2^{\prime}$ deoxycytidine-specific cleavage of the oligonucleotide-1 adduct was observed on heat treatment with piperidine $[28,29]$, interactions between the enediyne and an all 2 '-deoxycytidine oligonucleotide, $\mathrm{dC}_{8}$, were examined to determine whether or not the adducts could be isolated and studied. The mass spectrum obtained by FIA-ESI-MS analysis of a mixture incubated at $\mathrm{pH} 8$ revealed many ions containing $\mathrm{dC}_{8}$, most of which also contained up to three molecules of $\mathbf{1}$ per oligonucleotide (Figure 1a). Although the wide range of adducts formed indicated that 1 readily bound the 2'-deoxycytidine-rich oligonucleotide under these conditions and provided confirmation that ESI-MS could be used to detect the 

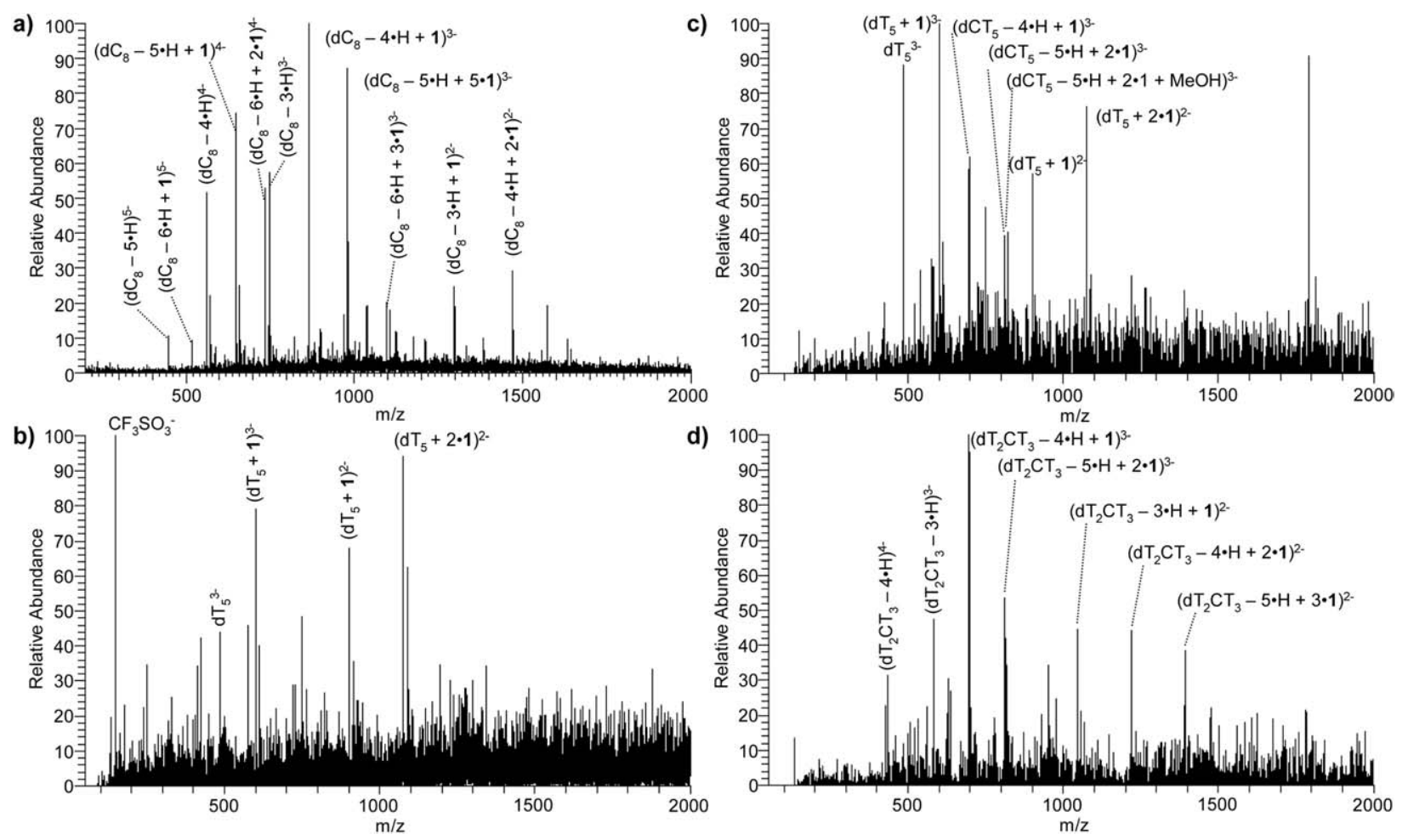

Figure 1. Mass spectra of $\mathbf{1}$ incubated with oligonucleotides. (a) $\mathrm{dC}_{8}$ incubated with $\mathbf{1} ;(\mathbf{b}) \mathrm{dCT}_{5}$ incubated with 1 at $\mathrm{pH} 8$; (c) $\mathrm{dCT}_{5}$ incubated with 1 at $\mathrm{pH}$ 6; (d) $\mathrm{dT}_{2} \mathrm{CT}_{3}$ incubated with 1 at $\mathrm{pH} 6$.

incubation products, the resulting ions revealed little about the mode of binding. Clearly, the sequence homogeneity precluded formation of one specific adduct structure and, thus, oligonucleotides containing a single $2^{\prime}$-deoxycytidine were used for more detailed structural studies, as described below.

\section{Interactions Between 1 and Either $d C T_{5}$ or $d T_{2} C T_{3}$}

Having established that 1 readily attaches to $2^{\prime}-$ deoxycytidine-containing oligonucleotides, we analyzed its interactions with two different sequences containing a single cytosine base. Previous studies indicated that DNA cleavage was observed on heat treatment with piperidine following incubation at higher $\mathrm{pH}$ values [28]. The ESI mass spectra of oligonucleotide/ $\mathbf{1}$ mixtures incubated at $\mathrm{pH} 8$ and $\mathrm{pH} 6$ yielded similar product ions. For instance, ESI-MS of the $\mathrm{dCT}_{5} / \mathbf{1}$ mixture incubated at $\mathrm{pH} 8$ (Figure $1 \mathrm{~b}$ ) primarily yielded several $\mathrm{dT}_{5}$ ions where cleavage occurred at the $\mathrm{P}-\mathrm{O}$ bond $5^{\prime}$ to the $2^{\prime}$-deoxythymine adjacent to the $2^{\prime}$-deoxycytidine. These ions had various charges, and several incorporated $\mathbf{1}$. The only ion from this spectrum absent in the ESI mass spectrum obtained for analogous mixture incubated at $\mathrm{pH} 6$ (Figure 1c) corresponded to the $\mathrm{CF}_{3} \mathrm{SO}_{3}^{-}$counter-ion. Since the $\mathrm{S} / \mathrm{N}$ of both of these mass spectra were modest due to the low concentrations and the minimal volumes of sample used for the FIA, our analysis focuses on the results for the samples incubated at $\mathrm{pH} 6$ because of the larger ion abundances and the greater numbers of ions observed. Whenever possible, CAD spectra were collected for the various adducts observed at both $\mathrm{pH}$ values, and the fragmentation patterns revealed no significant discrepancies.

FIA-ESI-MS analysis of the mixture of $\mathrm{dCT}_{5}$ and 1 incubated at $\mathrm{pH} 6$ yielded an assortment of product ions containing 1 (Figure 1c), and many of these products correspond to cleaved fragments of the oligonucleotide. In particular, several $\mathrm{dT}_{5}$ products, both alone and with one or two molecules of $\mathbf{1}$, were observed. The array of $\mathrm{dT}_{5}$ products results from cleavage on the $3^{\prime}$ side of the $2^{\prime}$-deoxycytidine of the $\mathrm{dCT}_{5}$ oligonucleotide and provide striking evidence for the expected heatinduced cleavage observed previously for this compound $[28,29]$. The selectivity for cleavage specific to the 2 -deoxycytidine position is remarkable. In addition to the $\mathrm{dT}_{5}$ products in Figure 1c, two adducts of the intact $\mathrm{dCT}_{5}$ oligonucleotide, $\left(\mathrm{dCT}_{5}-4 \cdot \mathrm{H}+1\right)^{3-}$ at 697 Th and $\left(\mathrm{dCT}_{5}-5 \cdot \mathrm{H}+2 \cdot 1+\mathrm{MeOH}\right)^{3-}$ at $822 \mathrm{Th}$, were observed along with two ions, at 749 and $1791 \mathrm{Th}$, for which formulas could not be assigned, but dissociated to yield fragments indicating the presence of both $\mathrm{dCT}_{5}$ and 1 (see below).

The product ions from Figure 1c with sufficient abundance, $\mathrm{dT}_{5}^{3-}$ at $485 \mathrm{Th},\left(\mathrm{dT}_{5}+1\right)^{3-}$ at $600 \mathrm{Th},\left(\mathrm{dCT}_{5}\right.$ $-4 \cdot \mathrm{H}+1)^{3-}$ at $697 \mathrm{Th}, 749 \mathrm{Th},\left(\mathrm{dCT}_{5}-5 \cdot \mathrm{H}+2 \cdot 1+\right.$ $\mathrm{MeOH})^{3-}$ at $822 \mathrm{Th},\left(\mathrm{dT}_{5}+\mathbf{1}\right)^{2-}$ at $901 \mathrm{Th},\left(\mathrm{dT}_{5}+2 \cdot 1\right)^{2-}$ at $1074 \mathrm{Th}$, and $1791 \mathrm{Th}$, were isolated and subjected to CAD. The resulting CAD mass spectra (Figure 2) reveal 

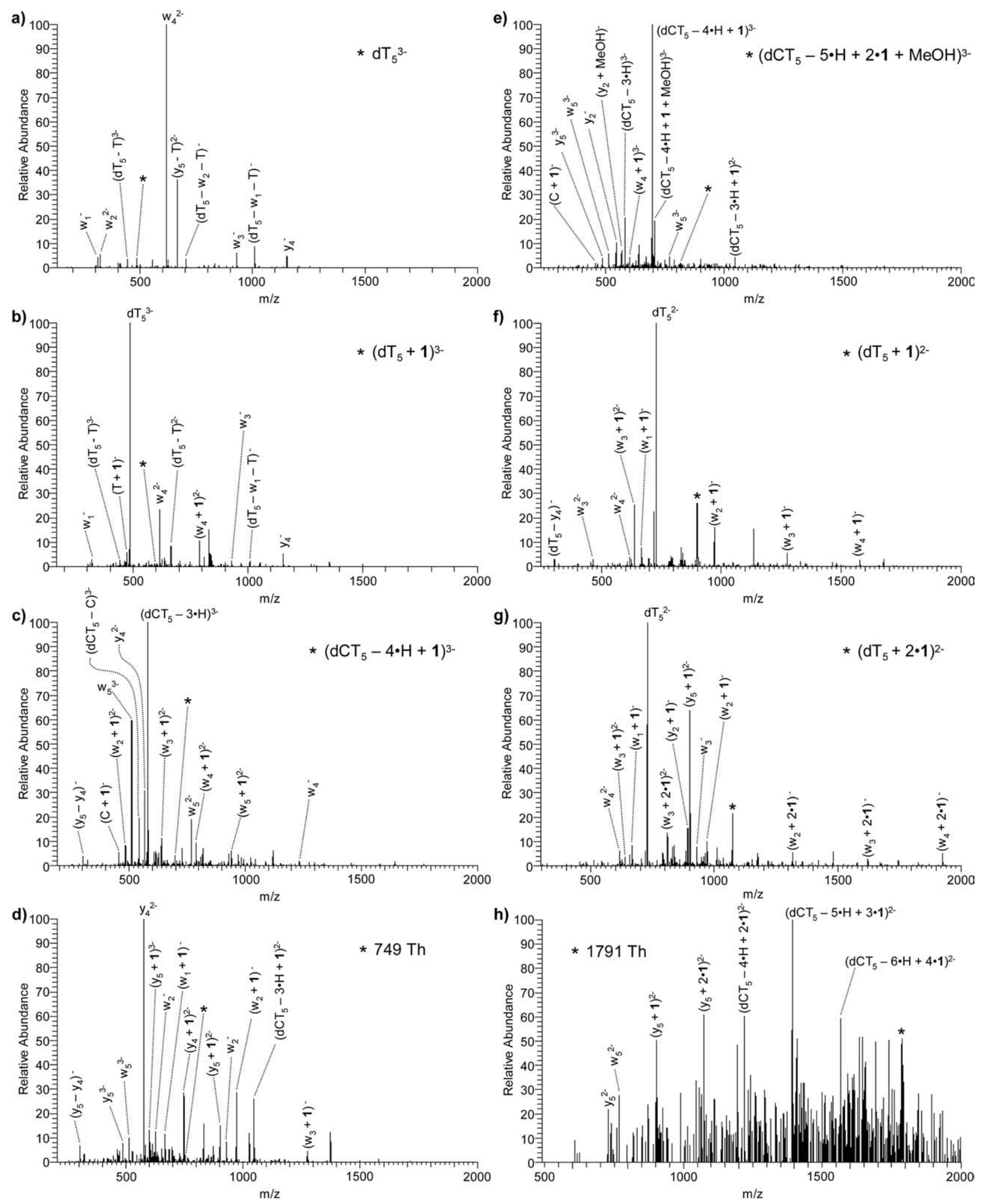

Figure 2. CAD of ions isolated from the mass spectrum of $\mathrm{dCT}_{5}$ incubated with $\mathbf{1}$ at $\mathrm{pH}$ 6. Parent ions were (a) $\mathrm{dT}_{5}^{3-}$ at $485 \mathrm{Th},(\mathbf{b})\left(\mathrm{dT}_{5}+\mathbf{1}\right)^{3-}$ at $\left.600 \mathrm{Th}, \mathrm{c}\right)\left(\mathrm{dCT}_{5}-4 \cdot \mathrm{H}+\mathbf{1}\right)^{3-}$ at $697 \mathrm{Th},(\mathrm{d}) 749 \mathrm{Th},(\mathbf{e})\left(\mathrm{dCT}_{5}\right.$ $-5 \cdot \mathrm{H}+2 \cdot \mathbf{1}+\mathrm{MeOH})^{3-}$ at $822 \mathrm{Th},(\mathbf{f})\left(\mathrm{dT}_{5}+\mathbf{1}\right)^{2-}$ at $901 \mathrm{Th},(\mathrm{g})\left(\mathrm{dT}_{5}+2 \cdot \mathbf{1}\right)^{2-}$ at $1074 \mathrm{Th}$, and (h) 1791 Th.

a combination of fragments resulting from ejection of $\mathbf{1}$ and backbone cleavages typical of CAD of oligonucleotides [36]. For the related $\mathrm{dT}_{5}$ parent ions (Figure 2a, b, $\mathrm{f}$, and $\mathrm{g}$ ), whenever the parent also contained $\mathbf{1}$, one dominant fragmentation pathway was ejection of $\mathbf{1}$, suggesting the molecule of $\mathbf{1}$ was only weakly attached 
to these oligonucleotide fragments containing only $2^{\prime}-$ deoxythymine residues. Of the backbone fragments observed, both $\mathrm{w}$ ions and $\left(\mathrm{dT}_{5}-\mathrm{w}-\right.$ base) ions, analogs to the (a - base) fragment ions typically produced upon activation of intact oligonucleotide ions, were observed. The fragmentation patterns of the $\left(\mathrm{dT}_{5}\right.$ $+1)^{-2}$ (Figure 2f) and $\left(\mathrm{dT}_{5}+2 \cdot 1\right)^{-2}$ ions (Figure $2 \mathrm{~g}$ ) are especially interesting because a variety of $\mathrm{w}_{\mathrm{n}}$ and $\left(\mathrm{w}_{\mathrm{n}}+\right.$ 1) fragment ions are observed, indicating that 1 likely can attach to any of the $2^{\prime}$-deoxythymine residues.

The striking prevalence of $3^{\prime}$ fragments in the CAD spectra of intact $\left(\mathrm{dCT}_{5}-4 \cdot \mathrm{H}+1\right)^{3-}$ and $\left(\mathrm{dCT}_{5}-5 \cdot \mathrm{H}+\right.$ $2 \cdot 1+\mathrm{MeOH})^{3-}$ ions is also noteworthy (Figure $2 \mathrm{c}$ and e). Although complementary fragments are typically observed, in these experiments $\mathrm{w}$ ions dominated the array of fragments while corresponding ( $\mathrm{a}-$ base) fragments were not observed. This may indicate localization of the positively-charged 1 on the $5^{\prime} 2^{\prime}$-deoxycytidine, precluding the formation of negatively-charged ( $\mathrm{a}-$ base) fragments. Lastly, CAD of the products at 749 and $1791 \mathrm{Th}$ with unassigned molecular formulas (Figure $2 \mathrm{~d}$ and $\mathrm{h}$ ) yielded fragments similar to those observed with the other parent ions, suggestive that these parents contained the intact $\mathrm{dCT}_{5}$ oligonucleotide, some number of $\mathbf{1}$, and some other unidentified species (such as counter-ions or solvent molecules).

Similar ESI-MS/MS analysis of the products obtained upon incubation of 1 with $\mathrm{dT}_{2} \mathrm{CT}_{3}$ yielded somewhat different results. In this case, except for a weakly abundant $\mathrm{w}_{2}$ adduct observed in the $\mathrm{pH} 8$ spectrum (data not shown), all of the products observed contained the intact oligonucleotide (Figure 1d). The fragments corresponding to cleavage at the 2'-deoxycytidine observed for the experiments with $\mathrm{dCT}_{5}$ described above were completely absent with $\mathrm{dT}_{2} \mathrm{CT}_{3}$. Also, a larger number of adducts of the intact oligonucleotide were formed, including: $\left(\mathrm{dT}_{2} \mathrm{CT}_{3}-4 \cdot \mathrm{H}+\mathbf{1}\right)^{3-},\left(\mathrm{dT}_{2} \mathrm{CT}_{3}-5 \cdot \mathrm{H}+2 \cdot \mathbf{1}\right)^{3-},\left(\mathrm{dT}_{2} \mathrm{CT}_{3}-\right.$ $3 \cdot \mathrm{H}+1)^{2-},\left(\mathrm{dT}_{2} \mathrm{CT}_{3}-4 \cdot \mathrm{H}+2 \cdot 1\right)^{2-}$, and $\left(\mathrm{dT}_{2} \mathrm{CT}_{3}-5 \cdot \mathrm{H}+\right.$ $3 \cdot 1)^{2-}$.

As before, the more abundant ions in Figure 1d, including $\left(\mathrm{dT}_{2} \mathrm{CT}_{3}-4 \cdot \mathrm{H}\right)^{4-}$ at $436 \mathrm{Th},\left(\mathrm{dT}_{2} \mathrm{CT}_{3}-\right.$ $3 \cdot \mathrm{H})^{3-}$ at $582 \mathrm{Th},\left(\mathrm{dT}_{2} \mathrm{CT}_{3}-4 \cdot \mathrm{H}+\mathbf{1}\right)^{3-}$ at $697 \mathrm{Th}$, $\left(\mathrm{dT}_{2} \mathrm{CT}_{3}-5 \cdot \mathrm{H}+\mathbf{2 \cdot 1}\right)^{3-}$ at $813 \mathrm{Th}, 951 \mathrm{Th},\left(\mathrm{dT}_{2} \mathrm{CT}_{3}-\right.$ $3 \cdot \mathrm{H}+\mathbf{1})^{2-}$ at $1046 \mathrm{Th},\left(\mathrm{dT}_{2} \mathrm{CT}_{3}-4 \cdot \mathrm{H}+2 \cdot \mathbf{1}\right)^{2-}$ at 1220 Th, and $\left(\mathrm{dT}_{2} \mathrm{CT}_{3}-5 \cdot \mathrm{H}+2 \cdot 1\right)^{2-}$ at $1392 \mathrm{Th}$, were isolated and subjected to CAD for structural characterization (Figure 3). In this case, although 3' fragments of the intact oligonucleotides were again most common, a fair number of the complementary ( $\mathrm{a}-$ base) ions were observed among fragments resulting from both adducted (Figure 3c, d, f, g, and h) and nonadducted (Figure 3a and $b$ ) oligonucleotides. The position of these backbone cleavages seemed to have no relation to the position of 2'-deoxycytidine in the oligonucleotide. Also, upon dissociation of the $1 / \mathrm{dT}_{2} \mathrm{CT}_{3}$ adducts, both adducted fragment ions (i.e., ones that contain 1) and non-adducted fragments (i.e., ones without 1 ) were generated in similar abundances. That this was consis- tently true regardless of the oligonucleotide sequence $\left(\mathrm{dT}_{2} \mathrm{CT}_{3}\right.$ versus $\left.\mathrm{dCT}_{5}\right)$ offers further evidence that the linkage between $\mathbf{1}$ and the oligonucleotide is at least of comparable strength to the internal covalent bonds in the oligonucleotide. CAD of the unassigned ion at 951 Th revealed that this ion contained both intact $\mathrm{dT}_{2} \mathrm{CT}_{3}$ and 1.

With both $\mathrm{dCT}_{5}$ and $\mathrm{dT}_{2} \mathrm{CT}_{3}$, more than a single molecule of 1 was observed bound to the oligonucleotide, which implies that despite the preference for reaction with cytosine previously observed [29], interactions with other sites on the oligonucleotide also occur. These multiply adducted species clearly cannot yield much information about the location of the enediyne, but an examination of the singly-adducted intact oligonucleotides reveals some clues. From the experiments with $\mathrm{dCT}_{5}$, the only suitable parent containing a single molecule of $\mathbf{1}$ was $\left(\mathrm{dCT}_{5}-4 \mathrm{H}+\mathbf{1}\right)^{3-}$. On fragmentation (Figure 2c), it yielded two different $\mathrm{w}$ fragments, $\mathrm{w}_{2}$ and $\mathrm{w}_{4}$, as well as an $\left(\mathrm{a}_{5}-\right.$ base $)$ fragment that each contained a molecule of 1 . Two possible scenarios can rationalize this behavior. First, 1 could be localized on the 2 -deoxythymine in the fifth position because it is the only residue contained in all three of the fragments. An alternative conclusion is that 1 did not localize at a specific site on the oligonucleotide sequence but, rather, the parent ion was a mixture of different adducted structures. Additionally, the cleaved ions in the parent spectrum, $\mathrm{dT}_{5}^{3-},\left(\mathrm{dT}_{5}+\mathbf{1}\right)^{3-},\left(\mathrm{dT}_{5}+\right.$ $\mathbf{1})^{2-}$, and $\left(\mathrm{dT}_{5}+2 \cdot 1\right)^{2-}$, also suggest that when 1 interacted with the cytosine it lead to subsequent cleavage either before or during the MS analysis.

An analogous intact adduct, $\left(\mathrm{dT}_{2} \mathrm{CT}_{3}-4 \cdot \mathrm{H}+1\right)^{3-}$, along with several other adducts between $\mathbf{1}$ and $\mathrm{dT}_{2} \mathrm{CT}_{3}$, were also examined. In these CAD mass spectra (Figure 3c, d, f, g, and h), nearly all the observed ions containing 1 also contained the 2'-deoxycytidine residue. Although it cannot be confirmed whether this results from localized or random attachment, in this case there is no apparent reason to discount the possibility of localization at the 2 -deoxycytidine. Also, the lack of cleaved ions in the ESI mass spectrum observed for the incubation of $\mathrm{dT}_{2} \mathrm{CT}_{3}$ with $\mathbf{1}$ (Figure $1 \mathrm{~d}$ ) supports that the 1-induced cleavage at 2 -deoxycytidine proceeds more readily with $5^{\prime}$ as opposed to internal 2 '-deoxycytidine residues.

\section{Interactions Between 1 and $d C C$ or $d G A$}

Experiments with the dinucleotide dCC incubated with 1 at $\mathrm{pH} 6$ yielded results indicative of the binding between the oligonucleotide and $\mathbf{1}$. In the negative mode typically used for DNA analysis due to the acidic phosphate backbone, the overall signal was low; however, $(\mathrm{dCC}+\mathbf{1}-\mathrm{H})^{-}$and $(\mathrm{dCC}+2 \cdot 1)^{-}$ions were detected in addition to the $\mathrm{CF}_{3} \mathrm{SO}_{3}^{-}$counter-ion (Figure 4a). With such a small oligonucleotide, however, the electrostatics are not necessarily dominated by the phosphate groups, and positive mode analysis becomes 

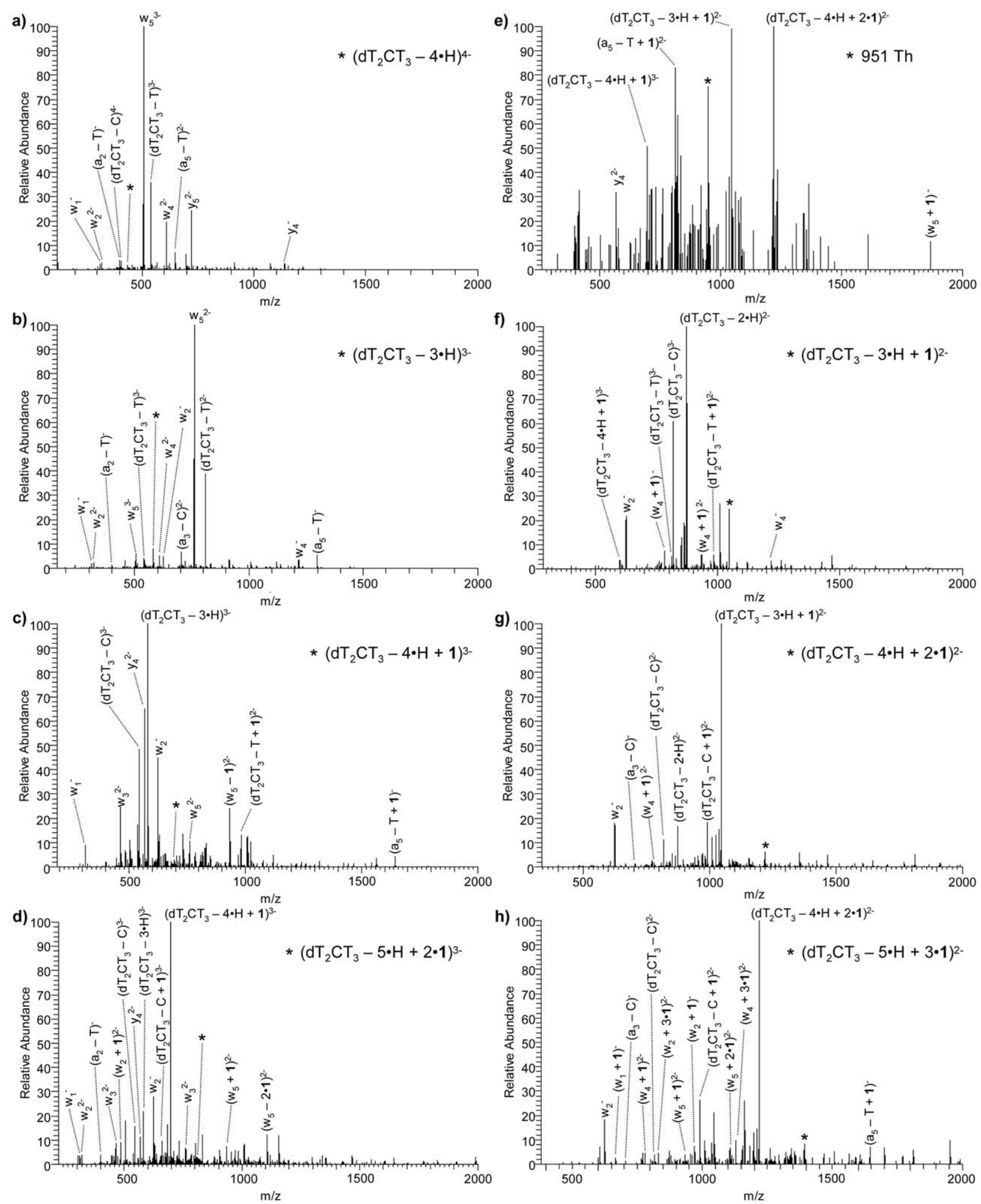

Figure 3. $\mathrm{CAD}$ of ions isolated from the mass spectrum of $\mathrm{dT}_{2} \mathrm{CT}_{3}$ incubated with 1 . Parent ions were (a) $\left(\mathrm{dT}_{2} \mathrm{CT}_{3}-4 \cdot \mathrm{H}\right)^{4-}$ at $436 \mathrm{Th},\left(\right.$ b) $\left(\mathrm{dT}_{2} \mathrm{CT}_{3}-3 \cdot \mathrm{H}\right)^{3-}$ at $582 \mathrm{Th},(\mathrm{c})\left(\mathrm{dT}_{2} \mathrm{CT}_{3}-4 \cdot \mathrm{H}+1\right)^{3-}$ at $697 \mathrm{Th}$, (d) $\left(\mathrm{dT}_{2} \mathrm{CT}_{3}-5 \cdot \mathrm{H}+2 \cdot 1\right)^{3-}$ at $813 \mathrm{Th},(\mathbf{e}) 951 \mathrm{Th},(\mathbf{f})\left(\mathrm{dT}_{2} \mathrm{CT}_{3}-3 \cdot \mathrm{H}+\mathbf{1}\right)^{2-}$ at $1046 \mathrm{Th},(\mathrm{g})\left(\mathrm{dT}_{2} \mathrm{CT}_{3}-\right.$ $4 \cdot \mathrm{H}+2 \cdot \mathbf{1})^{2-}$ at $1220 \mathrm{Th}$, and $(\mathbf{h})\left(\mathrm{dT}_{2} \mathrm{CT}_{3}-5 \cdot \mathrm{H}+2 \cdot \mathbf{1}\right)^{2-}$ at $1392 \mathrm{Th}$.

feasible (Figure $4 \mathrm{~b}$ ). In the positive mode, free $\mathbf{1}^{+}$was present in approximately equal abundance with the $(\mathrm{dCC}+\mathbf{1}+\mathrm{H})^{+}$ion. Other ions detected at lower abundances included the $(\mathrm{dCC}+2 \cdot \mathbf{1})^{2+}$ and $(\mathrm{dCC}+$ $2 \cdot 1)^{+}$ions.

On isolation of the $(\mathrm{dCC}+\mathbf{1})^{+}$ion, both with and 

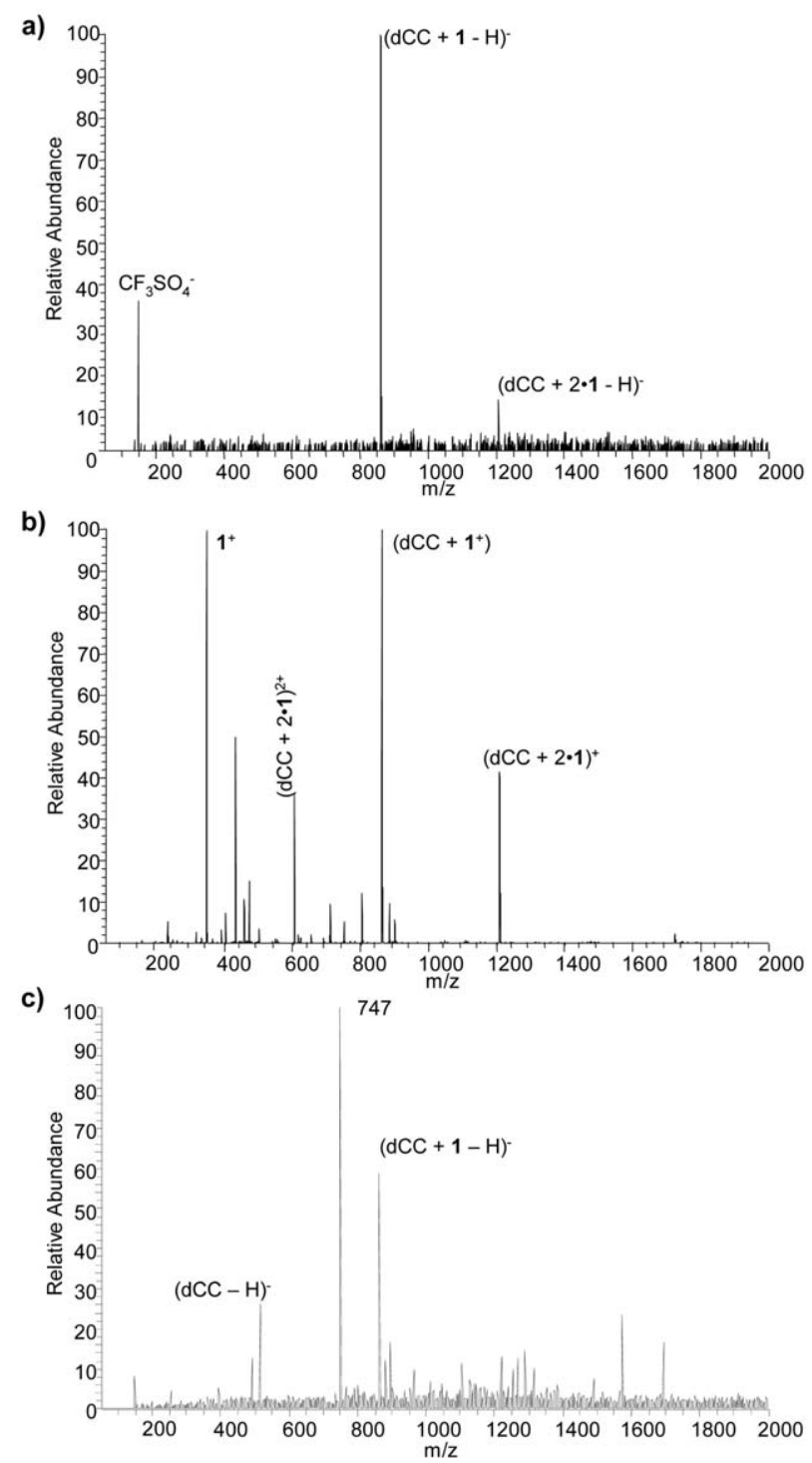

Figure 4. Mass spectrum of dCC incubated with 1 at $\mathrm{pH} 6$ collected for 50-2000 Th in (a) negative mode and (b) positive mode. (c) Mass spectrum of dCC incubated with $\mathbf{1}$ following a piperidine/heat treatment in the negative mode.

without a ${ }^{13} \mathrm{C}$ isotopic label at carbon one of the phenylethynyl group of $\mathbf{1}$ and subsequent fragmentation by CAD, two products related to ejection of $\mathbf{1}$ from the oligonucleotide, $(\mathrm{dCC}+\mathrm{H})^{+}$and $\mathbf{1}^{+}$, were observed. These species, however, were dwarfed by a product corresponding to an adduct between $\mathbf{1}$ and the cytosine nucleobase (Figure 5a) formed via detachment of the cytosine nucleobase from the deoxyribose of the dCC backbone. Likely, the product of a base-loss mechanism similar to the fragmentation commonly observed for CAD of oligonucleotides [36], the presence of this ion offers strong evidence for covalent attachment of $\mathbf{1}$ directly to the nucleobase.

To further probe the structure of this adduct, the $(\mathrm{C}$ $+1)^{+}$fragment was then isolated and subjected to a second stage of CAD (Figure $5 b$ ). An assortment of fragments resulted for which proposed structures are shown in Scheme 1. Through comparing the fragments observed both with and without the ${ }^{13} \mathrm{C}$ label at position 1, it was found that each of the ions shown retained the label upon fragmentation. For clarity, only the monoisotopic mass is listed although with the ${ }^{13} \mathrm{C}$ label, the ions were observed 1 Th greater. As shown in Scheme 1 , the position of the ${ }^{13} \mathrm{C}$ label in the structures is indicated with a dagger $(\dagger)$. The structures in Scheme 1 are consistent both with the observed $\mathrm{m} / \mathrm{z}$ values and the precursor structures. Scheme $\mathbf{1}$ shows $\mathbf{1}$ bound to the $5^{\prime}-2^{\prime}$-deoxycytidine rather than to the $3^{\prime}$ nucleotide. The ligand could be bound to either nucleotide without a discernible change in the mass spectra, and thus the $5^{\prime}$ adduct is depicted as one example of the proposed binding site of the ligand. The most abundant fragments resulted from detachment of the nucleobase leaving an intact $\mathbf{1}^{+}$ion at $\mathrm{m} / \mathrm{z} 347$ or the loss of a propynyl benzene yielding the ion at $342 \mathrm{Th}$. This 342 Th fragment ion along with the ones at 234 and 266 Th resulting from both the loss of a propynyl benzene and either the cytosine nucleobase or benzene, respectively, indicate that the enediyne binds to cytosine through the ethynyl benzene because attachment to the propynyl benzene fails to yield reasonable fragment structures for these masses. Other fragments observed correspond to losses of various parts of the cytosine nucleobase. One of these, the fragment at $364 \mathrm{Th}$, would be difficult to justify were the cytosine bound through the pyrimidine nitrogen rather than through the amine.

Since binding to thymine bases was observed for the longer oligonucleotides discussed earlier, a dinucleotide containing adenine and guanine was also studied to determine binding specificity. Upon incubation of dGA with 1, a dGA/1 complex was detected by ESI-MS (data not shown). CAD, including $\mathrm{MS}^{\mathrm{n}}$ experiments, of the resulting complexes indicated that $\mathbf{1}$ bound to either the guanine or adenine nucleobase.

\section{Piperidine/Heat Treatment of 1 and $d C C$ or $d G A$}

As with the longer oligonucleotides above, dCC samples were incubated with $\mathbf{1}$ and then subjected to a piperidine/heat treatment to initiate cleavage pathways and further characterize the interaction between 1 and the cytosine nucleobase. In the positive mode, new product ions of $\mathrm{m} / \mathrm{z} 432$ and 450, corresponding to 1 bound to piperidine or piperidine and water, respectively, in addition to new products of $\mathrm{m} / \mathrm{z} 332$ and 749 were observed. The most abundant product ion in the negative mode for the piperidine/heat treatment of $\mathbf{1}$ and dCC was observed at $m / z 747$ (Figure 4c). The ion of $\mathrm{m} / \mathrm{z} 332$ provides considerable insight into how piperidine binds to 1 . Isolation and dissociation of this ion confirms that the piperidine is bound to the propynyl benzene arm of $\mathbf{1}$, thus indicating that the cytosine binds to the other arm (ethynyl benzene arm) of $\mathbf{1}$. No cleavage products were seen in either the positive or negative ESI mass spectra. Due to the low masses of 

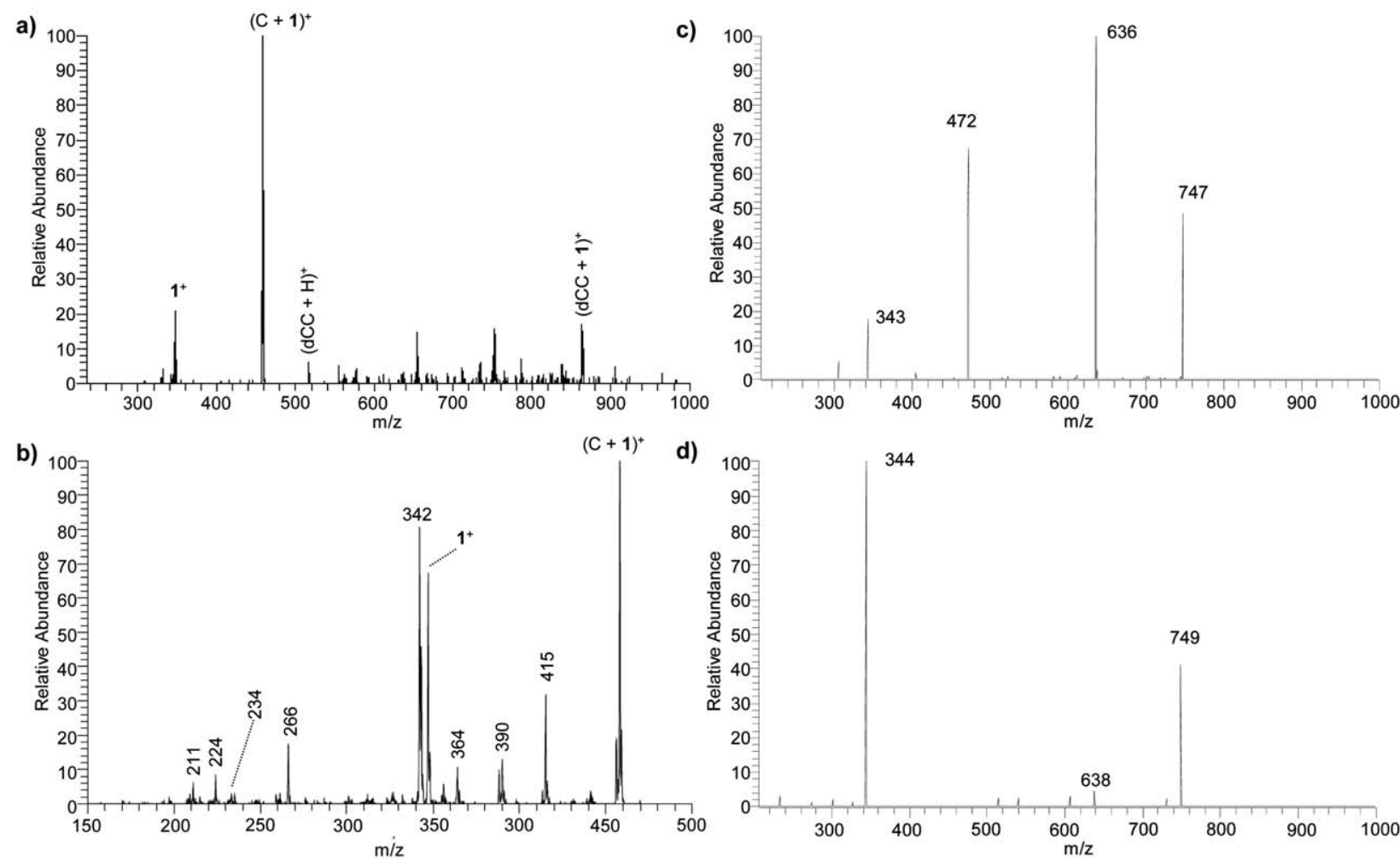

Figure 5. Tandem mass spectra of products ions from dCC incubated with $\mathbf{1}$ (a) and (b, or incubated with $\mathbf{1}$ followed by a piperidine/heat treatment (c) and (d). (a) CAD of $(\mathrm{dCC}+\mathbf{1})^{+}$at $863 \mathrm{Th}$. (b) CAD $\left(\mathrm{MS}^{3}\right.$ of $(\mathrm{C}+\mathbf{1})^{+}$at $458 \mathrm{Th}$ from the spectrum in (a). (c) CAD of $\mathrm{m} / \mathrm{z} 747$ from negative mode spectrum and (d) CAD of $\mathrm{m} / \mathrm{z} 749$ from positive mode spectrum of dCC incubated with $\mathbf{1}$ followed by piperidine/heat treatment.

possible cleavage products, products from piperidine induced cleavage could have inadvertently been lost during the ZipTip purification step.

The CAD mass spectra of the product ions of $m / z 747$ (negative) and $m / z 749$ (positive) are shown in Figure 5c and $d$, with substantial overlap between the two spectra. A proposed structure of the product generated upon the piperidine/heat treatment of $(\mathrm{dCC}+\mathbf{1})$ is shown in (Structure 2), along with assignments of the fragment ions resulting upon CAD of this product in the negative ion mode. For the $\mathrm{m} / \mathrm{z} 747$ precursor ion, the most abundant fragment ion results from the loss of the cytosine nucleobase, yielding the ion of $\mathrm{m} / \mathrm{z} 636$. Another abundant fragment ion of $m / z 472$ corresponds to a cleaved portion of dCC. The fragment ion of $\mathrm{m} / \mathrm{z}$ 343 corresponds to $(\mathrm{C}+\mathbf{1}-\text { propynyl benzene })^{-}$and confirms that 1 attaches to the $2^{\prime}$-deoxycytidine residue through the ethynyl benzene arm. For the $\mathrm{m} / \mathrm{z} 749$ precursor ion, the most abundant fragment ion of $\mathrm{m} / \mathrm{z}$ 344 corresponds to the cytosine nucleobase bound to the ethynyl benzene and fused ring of $\mathbf{1}$. Other less abundant fragment ions result from the loss of dCC, resulting in the fragment ion of $\mathrm{m} / \mathrm{z} 233$, and from the loss of the deoxyribonucleoside, yielding the fragment ion of $\mathrm{m} / \mathrm{z} 539$. While the fragmentation patterns of $\mathrm{m} / \mathrm{z}$ 747 and 749 indicated that these ions are not the result of piperidine induced backbone cleavage, they are consistent with a product structure in which dCC is bound to the ethynyl benzene arm of $\mathbf{1}$, which supports the proposed attachment site.

To evaluate the specificity of cleavage, the incubate of dGA and $\mathbf{1}$ was also subjected to the piperidine/heat treatment. There was no evidence of cleavage of [dGA +1 ], and the dinucleotide was the most abundant ion in the negative mode mass spectrum (data not shown). While 1 clearly can bind to nucleotides other than 2 '-deoxycytidine, the piperidine-induced cleavage appears to be specific for the cytosine nucleobase.

\section{Conclusions}

Electrospray ionization mass spectrometric analysis of carefully selected oligonucleotides incubated with the novel enediyne ligand 1 revealed several types of important clues about the interactions between $\mathbf{1}$ and DNA. First, 1 readily formed adducts of various stoichiometries with $\mathrm{dC}_{8}$ consistent with previous observations [29], and the mass analysis confirmed a direct interaction not mediated by metals or other compounds. Collisionally activated dissociation of these adducts revealed that, in many cases, both ejection of the ligand and DNA backbone cleavages occurred to similar extents, indicating that the interaction between $\mathbf{1}$ and DNA is of comparable strength to the bonds in the 


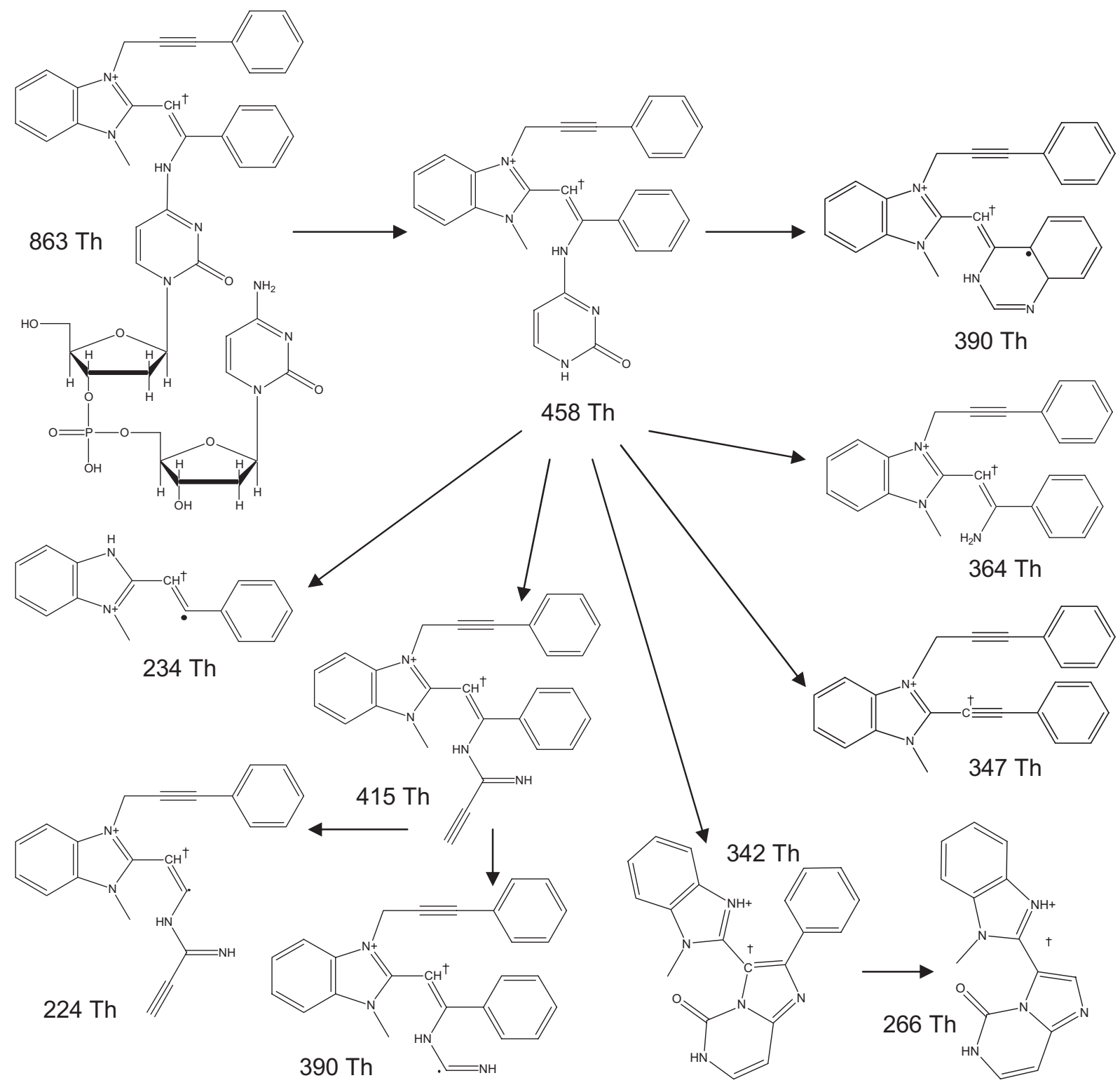

Scheme 1. Proposed CAD fragmentation pathway of $(\mathrm{dCC}+1)^{+}$.

oligonucleotide and suggesting that the DNA-1 adduct forms through a covalent linkage.

From a comparison of the interactions of $\mathbf{1}$ with $\mathrm{dCT}_{5}$ and $\mathrm{dT}_{2} \mathrm{CT}_{3}$ it became apparent that the extent of 2'-deoxycytidine-specific backbone cleavage induced by 1 varied significantly with the DNA sequence. When reacted under identical conditions, extensive cleavage of $\mathrm{dCT}_{5}$ adjacent to the 2 -deoxycytidine was observed in the mass spectrum, while only the intact oligonucleotide was observed for $\mathrm{dT}_{2} \mathrm{CT}_{3}$. Also, for both sequences extensive adduction of $\mathbf{1}$ was observed.

Lastly, evaluation of adducts formed between $\mathbf{1}$ and the dinucleotide $\mathrm{dCC}$ provided strong evidence for attachment of the enediyne directly to the cytosine nucleobase. Additional CAD studies of the cytosine-1 adduct provided an array of fragment ions consistent with the adduct forming through nucleophilic attack of the ethynyl benzene of $\mathbf{1}$ by the cytosine amino group.

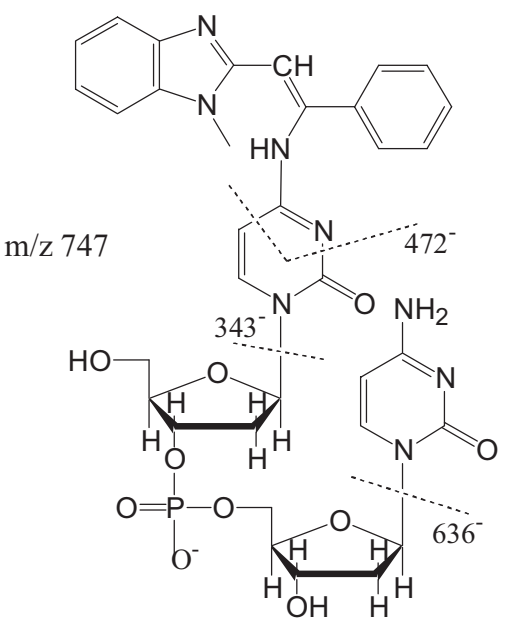

Structure 2 


\section{Acknowledgments}

The authors gratefully acknowledge support from the Robert A. Welch Foundation (F-1155) and NIH (RO1 GM65956).

\section{References}

1. Edo, K.; Mizugaki, M.; Koide, Y.; Seto, H.; Furihata, K.; Otake, N.; Ishida, N. The Structure of Neocarzinostatin Chromophore Possessing a Novel Bicyclo[7,3,0]dodecadiyne System. Tetrahedron Lett. 1985, 26, 331-334.

2. Nicolaou, K. C.; Dai, W.-M. Chemistry and Biology of the Enediyne Anticancer Antibiotics. Angew. Chem. Int Ed. Eng. 1991, 30, 1387-1416.

3. Nicolaou, K. C.; Smith, A. L.; Yue, E. W. Chemistry and Biology of Natural and Designed Enediynes. Proc. Natl. Acad. Sci. U.S.A. 1993, 90, 5881-5888.

4. Smith, A. L.; Nicolaou, K. C. The Enediyne Antibiotics. J. Med. Chem. 1996, 39, 2103-2117.

5. Galm, U.; Hager, M. H.; Van Lanen, S. G.; Ju, J.; Thorson, J. S.; Shen, B. Antitumor Antibiotics: Bleomycin, Enediynes, and Mitomycin. Chem. Rev. 2005, 105, 739-758.

6. Lee, M. D.; Dunne, T. S.; Siegel, M. M.; Chang, C. C.; Morton, G. O.; Borders, D. B. Calichemicins, a Novel Family of Antitumor Antibiotics. I. Chemistry and Partial Structure of Calichemicin $\gamma_{1}^{\mathrm{I}}$. J. Am. Chem. Soc. 1987, 109, 3464-3466.

7. Lee, M. D. Dunne, T. S. Chang C. C. Ellestad, G. A. Siegel, M. M. Morton, G. O.; McGahren, W. J.; Borders, D. B. Calichemicins, a Novel Family of Antitumor Antibiotics. II. Chemistry and Structure of Calichemicin $\gamma_{1}^{\mathrm{I}}$. J. Am. Chem. Soc. 1987, 109, 3466-3468.

8. Konishi, M.; Ohkuma, H.; Matsumoto, K.; Tsuno, T.; Kamei, H.; Miyaki, T. Oki, T.; Kawaguchi, H.; VanDuyne, G. D.; Clardy. J. Dynemicin A, a Novel Antibiotic with the Anthraquinone and 1,5-Diyn-3-ene Subunit. J. Antibiot. 1989, 42, 1449-1452.

9. Golik, J.; Clardy, J.; Dubay, G.; Groenewold, G.; Kawaguchi, H.; Konishi, M.; Krishnan, B.; Ohkuma, H.; Saitoh, K.; Doyle, T. W. Esperamicins, a Novel Class of Potent Antitumor Antibiotics. II. Structure of Esperamicin X. J. Am. Chem. Soc. 1987, 109, 3461-3462.

10. Golik, J.; Dubay, G.; Groenewold, G.; Kawaguchi, H.; Konishi, M.; Krishnan, B.; Ohkuma, H.; Saitoh, K.; Doyle, T. W. Esperamicins, a Novel Class of Potent Antitumor Antibiotics. III. Structure of Esperamicins $\mathrm{A}_{1}, \mathrm{~A}_{2}$, and $\mathrm{A}_{1 \mathrm{~b}}$. J. Am. Chem. Soc. 1987, 109, 3462-3464.

11. Jones, G. B.; Fouad, F. S. Designed Enediyne Antitumor Agents. Curr Pharm. Des. 2002, 8, 2415-2440.

12. Klein, M.; Walenzyk, T.; König, B. Electronic Effects on the Bergman Cyclization of Enediynes. A Review.Collect. Czech. Chem. Commun. 2004, 69, 945-965

13. McPhee, M. M.; Kerwin, S. M. Synthesis and Metal Ion Binding Studies of Enediyne-Containing Crown Ethers. J. Org. Chem. 1996, 61, 93859393.

14. Jones, G. B.; Wright, J. M.; Rush, T. M.; Plourde, G. W., II; Kelton, T. F.; Mathews, J. E.; Huber, R. S.; Davidson, J. P. Facile Unmasking of Dicobalt Hexacarbonyl Complexes of 1-Cyclodecene-3,9-Diynes (Enediynes). J. Org. Chem. 1997, 62, 9379-9381.

15. Dai, W.-M.; Lai, K. W.; Wu, A.; Hamaguchi, W.; Lee, M. Y. H.; Zhou, L.; Ishii, A.; Nishimoto, S. DNA. Cleavage Potency, Cytotoxicity, and Mechanism of Action of a Novel Class of Enediyne Prodrugs. J. Med. Chem. 2002, 45, 758-761.

16. Banfi, L.; Guanti, G. Synthesis of Intramolecularly Activated Lactenediynes and the Evaluation of Their Activity Against Plasmid DNA. Eur. J. Org. Chem. 2002, 22, 3745-3755.

17. Schmittel, M.; Viola, G.; Dall'Acqua, F.; Morbach, G. A Novel Concept to Activate Enediynes for DNA Cleavage. Chem. Commun. 2003, 5, 646-647.

18. Guanti, G.; Riva, R. Simplified Dynemicin Analogs: Diastereoselective Synthesis and Evaluation of Their Activity Against Plasmid DNA. Org. Biomol. Chem. 2003, 1, 3967-3976.

19. Suzuki, I.; Shigenaga, A.; Nemoto, H.; Shibuya, M. Synthesis and DNA Damaging Ability of Enediyne-Polyamine Conjugates. Tetrahedron Lett. 2004, 45, 1955-1959.

20. Usuki, T.; Inoue, M.; Hirama, M.; Tanaka, T. Rational Design of a Supra C-1027: Kinetically Stabilized Analog of the Antitumor Enediyne Chromoprotein. J. Am. Chem. Soc. 2004, 126, 3022-3023.

21. Suzuki, I.; Uno, S.; Tsuchiya, Y.; Shigenaga, A.; Hisao, N.; Shibuya, M. Synthesis and DNA Damaging Ability of Enediyne Model Compounds Possessing Photo-Triggering Devices. Bioorg. Med. Chem. Lett. 2004, 14, 2959-2962.

22. Fouad, F. S.; Crasto, C. F.; Lin, Y.; Jones, G. B. Photoactivated Enediynes: Targeted Chimeras which Undergo Photo-Bergman Cyclization. Tetrahedron. Lett. 2004, 45, 7753-7756.

23. Basak, A.; Roy, S. K.; Mandal, S. Activation of Macrocyclic Enediynes by Transannular Cyclization. Angew. Chem. Int. Ed. 2005, 44, 132-135.

24. Boger, D. L.; Zhou, J. CDPI. 3-Enediyne and CDPI3-EDTA Conjugates: A New Class of DNA Cleaving Agents. J. Org. Chem. 1993, 58, 3018-3024.

25. Toshima, K.; Ohta, K.; Ohashi, A.; Nakamura, T.; Nakata, M.; Matsumura, S. Design, Synthesis, and DNA Cleaving Profiles of Hybrids
Containing the Novel Enediyne and Naturally Occurring DNA Intercalators. J. Chem. Soc. Chem. Commun. 1993, 1525-1527.

26. Tokuda, M.; Fujiwara, K.; Gomibuchi, T.; Hirama, M.; Uesugi, M.; Sugiura, Y. Synthesis of a Hybrid Molecule Containing Neocarzinostatin Chromophore Analog and Minor Groove Binder. Tetrahedron. Lett. 1993, 34, 669-672.

27. David, W. M.; Kumar, D.; Kerwin, S. M. Synthesis of a Heterocyclic Aza-Enediyne and Its DNA-Cleavage Properties. Bioorg. Med. Chem. Lett. 2000, 10, 2509-2512.

28. Kumar, D.; David, W. M.; Kerwin, S. M. N-Propargyl-2-alkynylbenzothiazolium Aza-Enediynes: Role of the 2-Alkynylbenzothiazolium Functionality in DNA Cleavage. Bioorg. Med. Chem. Lett. 2001, 11, 2971-2974.

29. Tuntiwechapikul, W.; David, W. M.; Kumar, D.; Salazar, M.; Kerwin, S. M. DNA. Modification by 4-aza-3-ene-1,6-diynes: DNA Cleavage, pH-Dependent Cytosine-Specific Interactions, and Cancer Cell Cytotoxicity. Biochemistry 2002, 41, 5283-5290.

30. Sinha, S. C.; Li, L.-S.; Miller, G. P.; Dutta, S.; Rader, C.; Lerner, R. A. Prodrugs of Dynemicin Analogs for Selective Chemotherapy Mediated by an Aldolase Catalytic Ab. Proc. Natl. Acad. Sci. U.S.A. 2004, 101, 3095-3099.

31. Liebisch, G.; Drobnik, W.; Lieser, B.; Schmitz, G. High-Throughput Quantification of Lysophosphatidylcholine by Electrospray Ionization Tandem Mass Spectrometry. Clin. Chem. 2002, 48, 2217-2224.

32. Gooding, K. B.; Higgs, R.; Hodge, B.; Stauffer, E.; Heinz, B.; McKnight, K.; Philpps, K.; Shapiro, M.; Winkler, M.; Ng, W.-L.; Julian, R. K. High Throughput Screening of Library Compounds Against an Oligonucleotide Substructure of an RNA Target. J. Am. Soc. Mass Spectrom. 2004, 15, $884-892$.

33. Qian, J.; Voorbach, M. J.; Huth, J. R.; Coen, M. L.; Zhang, H.; Ng, S.-C.; Comess, K. M.; Petros, A. M.; Rosenberg, S. H.; Warrior, U.; Burns, D. J. Discovery of Novel Inhibitors of Bcl-xL Using Multiple High-Throughput Screening Platforms. Anal. Biochem. 2004, 328, 131-138.

34. Limbach, P. A. Indirect Mass Spectrometric Methods for Characterizing and Sequencing Oligonucleotides. Mass Spectrom. Rev. 1996, 15, 297-336.

35. Nordhoff, E.; Kirpekar, F.; Roepstorff, P. Mass Spectrometry of Nucleic Acids. Mass Spectrom. Rev. 1996, 15, 67-138.

36. McLuckey, S. A.; Van Berkel, G. J.; Glish, G. L. Tandem Mass Spectrometry of Small Multiply Charged Oligonucleotides. J. Am. Soc. Mass Spectrom. 1992, 3, 60-70.

37. Beck, J. L.; Colgrave, M. L.; Ralph, S. F.; Sheil, M. M. Electrospray Ionization Mass Spectrometry of Oligonucleotide Complexes with Drugs, Metals, and Proteins. Mass Spectrom. Rev. 2001, 20, 61-87.

38. Hofstadler, S. A.; Griffey, R. H. Analysis of Noncovalent Complexes of DNA and RNA by Mass Spectrometry. Chem. Rev. 2001, 101, 377-390.

39. Van den Driessche, B.; Lemiere, F.; Van Dongen, W.; Esmans, E. L. Structural Characterization of Melphalan Modified 2'-Oligodeoxynucleotides by Miniaturized LC-ES MS/MS. J. Am. Soc. Mass Spectrom. 2004, 15, 568-579.

40. Iannitti, P.; Sheil, M. M.; Wickham, G. High Sensitivity and Fragmentation Specificity in the Analysis of Drug-DNA Adducts by Electrospray Tandem Mass Spectrometry. J. Am. Chem. Soc. 1997, 119, 1490-1491.

41. Richter, S. N.; Menegazzo, I.; Fabris, D.; Palumbo, M. Concerted bis-Alkylating Reactivity of Clerocidin Towards Unpaired Cytosine Residues in DNA. Nucleic Acids Res. 2004, 32, 5658-5667.

42. Harsch, A.; Marzilli, L. A.; Bunt, R. C.; Stubbe, J.; Vouros, P. Accurate and Rapid Modeling of Iron-Bleomycin-Induced DNA Damage Using Tethered Duplex Oligonucleotides and Electrospray Ionization Ion Trap Mass Spectrometric Analysis. Nucleic Acids Res. 2000, 28, 1978-1985.

43. Hoes, I.; Van Dongen, W.; Lemiere, F.; Esmans, E. L.; Van Bockstaele, D.; Berneman, Z. N. Comparison Between Capillary and Nano Liquid Chromatography-Electrospray Mass Spectrometry for the Analysis of Minor DNA-Melphalan Adducts. J. Chromatogr. B Anal. Technol. Biomed. Life Sci. 2000, 748, 197-212.

44. Balcome S.; Park S.; Quirk Dorr, D. R. Hafner, L.; Phillips, L.; Tretyakova, N. Adenine-Containing. DNA-DNA Cross-Links of Antitumor Nitrogen Mustards. Chem. Res. Toxicol. 2004, 17, 950-962.

45. Wang, Y.; Zhang, Q.; Wang, Y. Tandem Mass Spectrometry for the Determination of the Sites of DNA Interstrand Cross-Link. J. Am. Soc. Mass Spectrom. 2004, 15, 1565-1571.

46. Wang, Y.; Wang, Y. Structure Elucidation of DNA Interstrand CrossLink by a Combination of Nuclease p1 Digestion with Mass Spectrometry. Anal. Chem. 2003, 75, 6306-6313.

47. Franska, M.; Franski, R. Schroeder, G. Springer, A - Beck, S. Linscheid, M. Electrospray Ionization Mass Spectrometric Study of Purine BaseCisplatin Complexes. Rapid Commun. Mass Spectrom. 2005, 19, 970-974.

48. Gupta, R.; Beck, J. L.; Sheil, M. M.; Ralph, S. F. Identification of Bifunctional GA and AG Intrastrand Cross-Links Formed Between Cisplatin and DNA. J. Inorg. Biochem. 2005, 9, 552-559.

49. Warnke, U.; Rappel, C.; Meier, H.; Kloft, C.; Galanski, M.; Hartinger, C. G.; Keppler, B. K.; Jaehde, U. Analysis of Platinum Adducts with DNA Nucleotides and Nucleosides by Capillary Electrophoresis Coupled to ESI-MS: Indications of Guanosine 5'-Monophosphate O6-N7 Chelation. Chem. Biochem. 2004, 5, 1543-1549.

50. Gupta, R.; Kapur, A.; Beck, J. L.; Sheil, M. M. Positive Ion Electrospray Ionization Mass Spectrometry of Double-Stranded DNA/Drug Complexes. Rapid Commun. Mass Spectrom. 2001, 15, 2472-2480.

51. Kung, A.; Strickmann, D. B.; Galanski, M.; Keppler, B. K. Comparison of the Binding Behavior of Oxaliplatin, Cisplatin, and Analogs to 5'-GMP in the Presence of Sulfur-Containing Molecules by Means of Capillary 
Electrophoresis and Electrospray Mass Spectrometry. J. Inorg. Biochem. 2001, 86, 691-698

52. Sturla, S. J.; Scott, J.; Lao, Y.; Hecht, S. S.; Villalta, P. W. Mass Spectrometric Analysis of Relative Levels of Pyridyloxobutylation Adducts Formed in the Reaction of DNA with a Chemically Activated Form of the Tobacco-Specific Carcinogen 4-(methylnitrosamino)-1-(3pyridyl)-1-Butanone. Chem. Res. Toxicol. 2005, 18, 1048-1055.

53. Borges, C.: Lemiere, F.; Embrechts, J.: van Dongen, W.: Esmans, E. L. Characterization of Estrone-Nucleic Acid Adducts Formed by Reaction of 3,4-Estrone-o-Quinone with 2'-Deoxynucleosides/Deoxynucleotides Using Capillary Liquid Chromatography/Electrospray Ionization Mass Spectrometry. Rapid Commun. Mass Spectrom. 2004, 18, 2191-2200.

54. Colgrave, M. L.: Iannitti-Tito, P.; Wickham, G.; Sheil, M. M. Rapid Determination of Sequence Selectivity and Stability of Alkylated Oligonucleotide Adducts by Electrospray Tandem Mass Spectrometry. Aust. J. Chem. 2003, 56, 401-413.
55. Inagaki, S.; Esaka, Y.; Deyashiki, Y.; Sako, M.; Goto, M. Analysis of DNA Adducts of Acetaldehyde by Liquid Chromatography-Mass Spectrometry. J. Chromatogr. A 2003, 987, 341-347.

56. Little, D. P.; Chorush, R. A.; Speir, J. P.; Senko, M. W.; Kelleher, N. L.; McLafferty, F. W. Rapid Sequencing of Oligonucleotides by HighResolution Mass Spectrometry. I. Am. Chem. Soc. 1994, 116, 4893-4897.

57. Little, D. P.; Speir, J. P.; Senko, M. W.; O'Connor, P. B.; McLafferty, F. W. Infrared Multiphoton Dissociation of Large Multiply Charged Ions for Biomolecule Sequencing. Anal. Chem. 1994, 66, 2809-2815.

58. Keller, K. M.; Brodbelt, J. S. Collisionally Activated Dissociation and Infrared Multiphoton Dissociation of Oligonucleotides in a Quadrupole Ion Trap. Anal. Biochem. 2004, 326, 200-210.

59. Schultz, K. N.; Håkansson, K. Rapid Electron Capture Dissociation of Mass-Selectively Accumulated Oligodeoxynucleotide Dications. Int. J. Mass Spectrom. 2004, 234, 123-130. 